\title{
ANÁLISE DO DESGASTE PRODUZIDO NO PREPARO DE CANAIS RADICULARES COM O SISTEMA OSCILATÓRIO EM TRÊS DIFERENTES VELOCIDADES
}

\author{
ANALYSIS OF THE PRODUCED CONSUMING IN THE ROOT CANALS PREPARATION WITH THE OSCILLATORY \\ SYSTEM IN THREE DIFFERENT SPEEDS
}

\author{
Orlando Limongi * \\ Anelise Vieira Bernardes ** \\ Patrícia Rodriguez Silveira Netto ** \\ Tiago André Fontoura de Melo *** \\ Renata Grazziotin Soares ****
}

\begin{abstract}
RESUMO
Introdução: Este estudo avalia, in vitro, a quantidade de desgaste produzido por instrumentos endodônticos de aço inoxidável, acionados a um sistema automatizado de movimento oscilatório, em três diferentes velocidades: 6.000, 8.000 e 10.000 rotaçôes por minuto. Métodos: Para isso, foram utilizadas 18 raízes palatinas de molares superiores, que foram distribuídas aleatoriamente em três grupos experimentais e individualmente pesadas em uma balança digital analítica, antes e depois do preparo endodôntico. Resultado e Conclusão: A comparação entre as médias de pesagem obtidas em cada grupo possibilitou concluir que não houve diferença estatística significativa quanto à quantidade de desgaste produzido entre as três velocidades testadas.
\end{abstract}

DESCRITORES: Endodontia • Instrumentos odontológicos • Preparo de canal radicular • Teste de materiais.

\begin{abstract}
Introduction: This study evaluates, in vitro, the amount of produced consuming for stainless steel endodontic instruments, defendant in an automatized system of oscillatory movement, in three different speeds: $6.000,8.000$ and 10.000 rotations per minute. Methods: For this, 18 palatines root canals of superior molar superiors had been used, that had been randomly distributed in three individually weights in experimental groups and in an analytical digital scale before and after the endodontic preparation. Result and Conclusion: The comparison between the averages of weight in each group made possible to conclude that there were no significant statistical difference to the amount of consuming produced among of the three tested speeds.
\end{abstract}

DESCRIPTORS: Endodontics $\bullet$ Instruments dental $\bullet$ Root canal preparation $\bullet$ Materials testing.

\footnotetext{
* Doutor em Endodontia. Professor do Curso de Odontologia da Universidade Luterana do Brasil - Campus Canoas/RS

** Especialista em Endodontia pela Universidade Luterana do Brasil - Campus Canoas/RS

*** Mestre em Endodontia pela Universidade Luterana do Brasil - Campus Canoas/RS

**** Mestranda em Endodontia do Programa de Pós-Graduação em Odontologia da Universidade Luterana do Brasil - Campus Canoas/RS
} 
Limongi O, Bernardes AV, Silveira Netto PR, MeloTAF, Soares RG. Análise do desgaste produzido no preparo de canais radiculares com o sistema oscilatório em três diferentes velocidades. Revista de Odontologia da Universidade Cidade de São Paulo 2009 jan-abr; 21(1): 14-7

\section{INTRODUÇÃO}

O preparo químico-mecânico dos canais radiculares é uma das etapas mais importantes para se obter o sucesso no tratamento endodôntico. Essa etapa é realizada pela adequada limpeza e modelagem dos canais, que é conseguida por meio da ação mecânica de instrumentos endodônticos manuais e/ou automatizados, aliadas à ação química de soluçôes irrigadoras.

Segundo Cohen e Burns ${ }^{1}$ (2000), ao final do preparo endodôntico, o canal radicular deve ser uma réplica da sua configuração original, em forma e conicidade, porém com um maior diâmetro.

Com o objetivo de realizar uma correta modelagem e limpeza junto a canais radiculares que apresentam condiçóes anatômicas desfavoráveis, além de diminuir o tempo operatório e consequentemente evitar a fadiga do paciente e do profissional, sistemas automatizados foram introduzidos na endodontia. Dentre esses sistemas, destacam-se os aparelhos automatizados de movimentos oscilatórios (Sydney', 2002).

Esses dispositivos, além de serem viáveis em relação ao custo, possuem a vantagem de poderem ser utilizados tanto com instrumentos endodônticos de aço inoxidável quanto de níquel-titânio, e serem acionados por meio de micromotores convencionais (pneumáticos) ou por motores elétricos.

Ao optar pelo uso de instrumentos de aço inoxidável junto às peças automatizadas, inúmeros são os relatos na literatura acerca das propriedades desses instrumentos, como a capacidade de corte e a memória molecular elástica do material.

No que diz respeito aos desvios apicais provocados por instrumentos de aço inoxidável utilizados manualmente, há na literatura vários relatos. Porém, poucos relativos ao seu uso junto a sistemas automatizados de movimentos oscilatórios.

Em 2002, Sydney ${ }^{9}$ analisou, in vitro, a ocorrência de desvio apical no preparo de canais mésio-vestibulares de primeiros molares superiores, empregando os sistemas oscilatórios M4 (Kerr), Endo Gripper (Moyco Union Broach) e contra-ângulo Kavo, comparando-os à técnica manual. Esse estudo mostrou uma incidência de desvios apicais de $14,28 \%$ para os três sistemas de movimentos oscilatórios e de $21,4 \%$ para o grupo em que o preparo foi realizado manualmente.

Clinicamente, independente do sistema automatizado de movimentos oscilatórios, os resultados têm se mostrado muito satisfatórios, contribuindo significati- vamente para melhorar o trabalho do endodontista, e para preparar o canal radicular com rapidez e eficiência, constituindo-se em auxiliares de grande valor do tratamento endodôntico.

Diante disso, o objetivo deste estudo é avaliar a quantidade de desgaste de dentina promovido pelo sistema automatizado de movimento oscilatório acionado por motor elétrico com o uso de instrumentos endodônticos de aço inoxidável em três diferentes velocidades.

\section{MATERIAIS E MÉTODOS}

Para isso, foram utilizadas 18 raízes palatinas de molares superiores que não apresentassem manipulação endodôntica prévia, rizogênese incompleta ou reabsorção dentária. Todas as raízes selecionadas tinham $15 \mathrm{~mm}$ de comprimento de forma padronizada.

Mediante irrigação/aspiração com solução de hipoclorito de sódio a $1 \%$, realizou-se manualmente a exploração dos canais radiculares com instrumentos endodônticos de aço inoxidável tipo K \#10 (Dentsply Maillefer). A partir de então, estabeleceu-se o comprimento de trabalho de cada raiz, subtraindo-se $1 \mathrm{~mm}$ do comprimento apresentado pelo instrumento na justaposição à saída foraminal.

Após, preparou-se cada canal, manualmente, por meio de um único operador, com instrumento tipo $\mathrm{K}$, em movimento de limagem, sequencialmente nos números \#15, \#20 e \#25. Cada instrumento foi utilizado para o preparo de três canais radiculares.

As raízes foram entáo distribuídas aleatoriamente em três diferentes grupos de seis elementos cada um, onde respectivamente utilizaram-se as velocidades de 6.000, 8.000 e 10.000 rotaçóes por minuto.

Após permanecerem por 7 dias em solução de hipoclorito de sódio a $1 \%$, as amostras foram removidas deste meio e exposta em uma mesa à temperatura ambiente por mais 7 dias, quando, então, realizou-se a pesagem inicial.

O peso inicial de cada amostra foi determinado por meio de uma balança analítica (Mettler AJ150) a partir da média aritmética de 3 pesagens efetuadas individualmente. A unidade de peso usada foi o grama.

Concluídas as fases preliminares, executaram-se os preparos dos canais radiculares, com a utilização de contra-ângulo de sistema automatizado de movimentos oscilatórios (NSK - Adiel Super Endo) com redutor de velocidade de 10:1 acoplado em motor elétrico (TC 3000 - Cosa Dental), nas três diferentes velocidades testadas. 
Limongi O, Bernardes AV, Silveira Netto PR, Melo TAF, Soares RG. Análise do desgaste produzido no preparo de canais radiculares com o sistema oscilatório em três diferentes velocidades. Revista de Odontologia da Universidade Cidade de São Paulo 2009 jan-abr; 21 (1): 14-7

A técnica utilizada para o preparo químico-mecânico foi a sequencial por meio de movimentos de limagem com os instrumentos \#30, \#35, \#40, \#45 e \#50. O tempo de utilização de cada instrumento no interior do canal ficou estabelecido em 1 minuto. A cada troca de instrumento, realizou-se irrigação/aspiração com 2 $\mathrm{ml}$ de solução de hipoclorito de sódio a $1 \%$ com o uso intercalado do instrumento \#10. Concluído o preparo, cada amostra foi irrigada com $1 \mathrm{ml}$ de EDTA, o qual foi agitado mediante uso do mesmo instrumento durante 3 minutos e, finalmente, irrigado com solução de hipoclorito de sódio a $1 \%$ sendo recolocadas em seus respectivos recipientes contendo esta solução.

Após 7 dias da finalizaçáo dos preparos, as amostras foram retiradas de seus recipientes e novamente expostas à temperatura ambiente por mais 7 dias, quando se procedeu à pesagem final. $\mathrm{Na}$ pesagem final foram estabelecidos os mesmos critérios de pesagem inicial.

Com os dados obtidos na pesagem, nos dois momentos, foi feita a análise estatística através do teste não-paramétrico Kruskal-Wallis ao nível de significância de 5\%.

\section{RESULTADOS}

$\mathrm{Na}$ comparação da influência da velocidade de acionamento dos instrumentos endodônticos junto ao desgaste da parede destinária do canal radicular, não houve diferença estatística significativa entre os três grupos experimentais (Tabela 01 e Gráfico 01) $(\mathrm{p}=0,32)$.

\section{DISCUSSÃO}

A busca por uma melhor qualidade no preparo de canais radiculares, bem como o aumento da produtividade e redução do tempo e esforço dispensados, acabaram por culminar com o surgimento dos preparos automatizados.

A proposta inicial de uso dos sistemas automatizados de movimentos oscilatórios seria a de acionamento pneumático, uma vez que podem ser acoplados ao micro-motor convencional. Porém, cogita-se corretamente que a saída de ar nos compressores não obedecem a uma constância, o que poderia influenciar negativamente na

Tabela 01 - Comparação estatística entre os três grupos experimentais.

\begin{tabular}{ccccc}
\hline Diferença & $\mathbf{n}$ & Media $(\boldsymbol{g})$ & Desvio-padrão & $\mathbf{p}$ \\
\hline Grupo 1 & 6 & 0,01751 & 0,00439 & 0,32 \\
Grupo 2 & 6 & 0,01844 & 0,00622 & \\
Grupo 3 & 6 & 0,03102 & 0,02014 & \\
\hline
\end{tabular}

cinemática dos instrumentos, promovendo distorçóes ou até mesmo acidentes (Lopese Siqueira $\left.{ }^{5}, 2004\right)$.

Diante disto, há trabalhos que propóem o uso de motores elétricos no acionamento de tais peças (Limongi et al. ${ }^{3-4}, 2004 a$ e 2004b). Porém, não há na literatura um consenso sobre qual velocidade deva ser empregada quando do uso desses motores.

Quanto à metodologia empregada, foram utilizados para a pesquisa raízes palatinas de primeiros molares superiores por serem, na sua maioria, raízes relativamente retas. Para padronizar, optou-se por utilizar raízes com o mesmo comprimento de trabalho (14mm).

No preparo dos canais, utilizou-se uma técnica sequencial de limagem. Iniciou-se com o instrumento tipo K \#10 para exploração e medição do canal. Após, foram utilizados os instrumentos endodônticos \#15, \#20 e \#25 para padronizar o diâmetro dos canais antes do uso do sistema automatizado de movimento oscilatório (Pereira et al. $\left.{ }^{7}, 2003\right)$. Assim, todas as raízes partiram do mesmo diâmetro. Depois, com o uso do sistema automatizado de movimentos oscilatórios (NSK) e motor elétrico utilizaram-se os instrumentos \#30, \#35, \#40, \#45 e \#50.

Ao final do preparo, optou-se pelo uso do EDTA para remoção da smear-layer para que sua permanência não influenciasse no peso final.

A padronização da pesagem em função da secagem dos dentes após a hidratação foi realizada, como nos estudos de Pesce $^{8}$ (1990), Hennequin et al. ${ }^{2}$ (1992) e Medeiros et al. ${ }^{6}$ (2000).

Para a análise dos resultados, optou-se por um teste não-paramétrico em função dos dados não terem distribuição normal. Ou seja, o número de amostras por grupo foi pequeno.

No Gráfico 1, pode-se observar que a média de des-

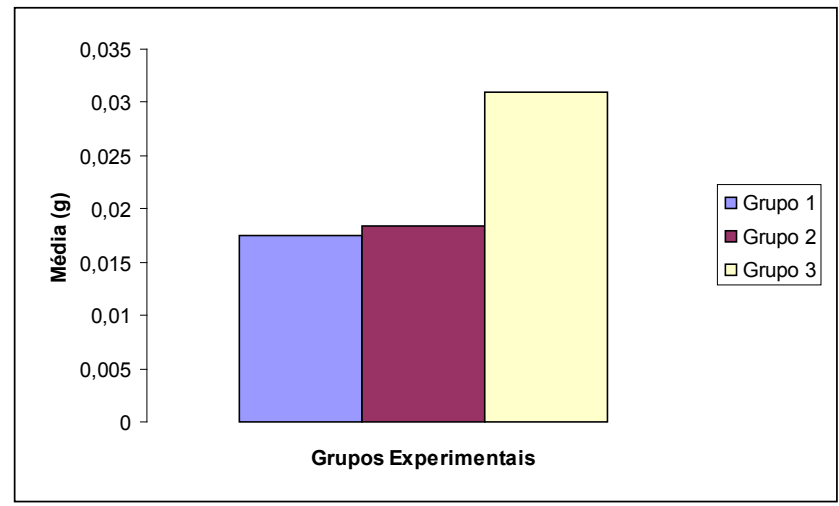

Gráfico 1 - Gráfico representativo da média da diferença de peso das amostras nos três grupos experimentais. 
Limongi O, Bernardes AV, Silveira Netto PR, MeloTAF, Soares RG. Análise do desgaste produzido no preparo de canais radiculares com o sistema oscilatório em três diferentes velocidades. Revista de Odontologia da Universidade Cidade de São Paulo 2009 jan-abr; 21(1): 14-7

gaste produzido no Grupo $1(0,01751)$ foi menor que no Grupo $2(0,01844)$ e no Grupo 3 (0,03102), podendo-se dizer que foi produzido mais desgaste de dentina no Grupo 3 que nos Grupos 1 e 2. Possivelmente porque a velocidade no Grupo 3 (10.000 rpm) foi maior que no Grupo 1 (6.000 rpm) e no $2(8.000 \mathrm{rpm})$, proporcionando um aumento da repetiçáo do contato dos instrumentos com as paredes do canal radicular. Porém, essa diferença entre os grupos experimentais não foi estatisticamente significativa.

\section{CONCLUSÕES}

A quantidade de desgaste da dentina no interior do canal radicular promovido pelo sistema automatizado de movimento oscilatório acionado por motor elétrico com o uso de instrumentos endodônticos de aço inoxidável não apresentou diferença significativa ao nível estatístico de $5 \%$ entre as velocidades de acionamento testadas. A quantidade de dentina removida foi sequencialmente maior quando do emprego de velocidades maiores.

\section{REFERÊNCIAS}

1. Cohen S, Burns R. Caminhos da polpa, $7^{\mathrm{a}} \mathrm{ed}$. Rio de Janeiro:Guanabara Koogan; 2000.

2. Hennequin M, Andre JF, Botta G. Dentin removal efficiency of six endodontic systems: a quantitative comparison. J Endod. 1992 Dec; 18(12):601-4.

3. Limongi $\mathrm{O}$, Ramos IFA, Troian $\mathrm{CH}$, Vanni JR, Albuquerque DS, Baratto Filho F. Análise in vitro do desvio apical, observado no sentido proximal, produzido por dois sistemas de rotação alternada: endo-gripper e M4. J Bras Endondontia. 2004 jan/mar; 5(16): 67-72.

4. Limongi O, Klymus AO, Baratto Filho F, Vanni JR, Travassos R. In vitro evaluation of the presence of apical deviation with employment of automated handpieces with continuous for root canal preparation. J Appl Oral Sci. 2004 Jul/Sep; 12(3):195-9.

5. Lopes H, Siqueira JF. Endodontia: biologia e técnica, $2^{\text {nd }}$ ed. Rio de Janeiro: Guanabara Koogan; 2004.

6. Medeiros JMF, Simi Jr J, Risso VA. Estudo comparativo mediante pesagem de duas técnicas de preparo de canais radiculares curvos com um tipo de instrumento endodôntico. Rev Odontol Univ Ribeirão Preto. 2000; 3(1):11-6.
7. Pereira CC, Barletta FB, Santarosa CT, Masiero AV, Vier FV, Ramires FB. Estudo comparativo, in vitro, entre peças mecanizadas no preparo do canal radicular, em função da perda de massa dentinária. In: 20 Reunião Anual da SBPqO; 2003; Águas de Lindóia. São Paulo: Pesquisa Odontológica Brasileira; 2003 v. 17 p. 115.

8. Pesce HF. Avaliação comparativa "in vitro", mediante a pesagem de dentes humanos, da eficiência de corte das limas Trifile e Flexofile, segundo o número de uso e o operador [Doutorado]. São Paulo: Faculdade de Odontologia da Universidade de São Paulo; 1990.

9. Sydney GB. Como preparar o canal radicular com rapidez e eficiência. In: Rielson JAC, Gonçalves ERN. Endodontia e trauma. São Paulo: Artes Médicas; 2002.

Recebido em: 18/07/2008

Aceito em: 18/11/2008 